\title{
RESOLVENT OPERATOR METHOD FOR GENERAL VARIATIONAL INCLUSIONS
}

\author{
EMAN AL-SHEMAS
}

\begin{abstract}
In this paper, we introduce a new class of variational inclusions involving three operator. Using the resolvent operator technique, we establish the equivalence between the general variational inclusions and the resolvent equations. We use this alternative equivalent formulation to suggest and analyze some iterative methods for solving the general variational inclusions. We also consider the criteria of these iterative methods under suitable conditions. Since the general variational inclusions include the variational inequalities and the related optimization problems as special cases, our results continue to hold for these problems.
\end{abstract}

Mathematics subject classification (2000): 49J40, 90C33.

Keywords and phrases: variational inclusion, approximation methods, resolvent equations, variational inequalities.

\section{REFERENCES}

[1] W. F. Ames, Numerical Methods for Partial Differential Equations, Third Edition, Academic Press, New York, 1992.

[2] C. Baiocchi, A. Capelo, Variational and Quasi-Variational Inequalities, J. Wiley and Sons, New York, London, 1984.

[3] A. Bnouhachem, M. Aslam Noor and T. M. Rassias, Three-step iterative algorithms for mixed variational inequalities, Appl. Math. Comput., 183 (2006), 436-446.

[4] A. Bnouhachem, M. Aslam Noor, Numerical comparison between prediction-correction methods for general variational inequalities, Appl. Math. Comput., 186 (2007), 496-505.

[5] H. BreZIS, Operateurs Maximaux Monotone et Semigroups de Contractions dan Espaces de Hilbert, North-Holland, Amsterdam, 1973.

[6] R.W. Cottle, F. Giannessi, J.L. Lions, Variational Inequalities and Complementarity Problems: Theory and Applications, J. Wiley and Sons, New York, 1980.

[7] J. ECKSTEIn, B. P. BeRTSEKAS, On the Douglas-Rachford splitting method and the proximal point algorithm for maximal monotone operators, Math. Prog., 55 (1992), 293-318.

[8] M. FUKUSHIMA, The primal Douglas-Rachford splitting algorithm for a class of monotone operators with applications to the traffic equilibrium problem, Math. Prog., 72 (1996), 1-15.

[9] F. Giannessi, A. Maugeri, Variational Inequalities and Network Equilibrium Problems, Plenum Press, New York, 1995.

[10] R. Glowinski, J.L. Lions, R. Trémolières, Numerical Analysis of Variational Inequalities, North-Holland, Amsterdam, 1981.

[11] S. Haubruge, V. H. Nguyen, J. J. Strodiot, Convergence analysis and applications of the Glowinski-Le Tallec splitting method for finding a zero of the sum of two maximal monotone operators, J. Optim. Theory Appl., 97 (1998), 645-673.

[12] P. L. Lions, B. Mercier, Splitting algorithms for the sum of two nonlinear operators, SIAM J. Numer. Anal., 16 (1979), 69-76.

[13] A. Moudafi, M. Thera, Finding a zero of the sum of two maximal monotone operators, J. Optim. Theory Appl., 97 (1997), 425-448.

[14] A. Moudafi, M. Aslam Noor, Sensitivity analysis of variational inclusions by the Wiener-Hopf equations technique, J. Appl. Math. Stochastic Anal., 12 (1999), 223-232. 
[15] M. Aslam Noor, Some algorithms for general monotone mixed variational inequalities, Math. Computer Modelling, 29, 7 (1999), 1-9.

[16] M. Aslam Noor, Algorithms for general monotone mixed variational inequalities, J. Math. Anal. Appl., 229 (1999), 330-343.

[17] M. ASLAM NOOR, An extraresolvent method for monotone mixed variational inequalities, Math. Computer Modelling, 29 (1999), 95-100.

[18] M. ASLAM NoOR, Some recent advances in variational inequalities, Part I, basic concepts, New Zealand J. Math., 26 (1997), 53-80.

[19] M. ASlam Noor, Some recent advances in variational inequalities, Part II, other concepts, New Zealand J. Math., 26 (1997), 229-255.

[20] M. Aslam Noor, Generalized set-valued variational inclusions and resolvent equations, J. Math. Anal. Appl., 228 (1998), 206-220.

[21] M. Aslam Noor, Set-valued mixed quasi variational inequalities and implicit resolvent equations, Math. Computer Modelling, 29 (1999), 1-11.

[22] M.A. Noor, New approximation schemes for general variational inequalities, J. Math. Anal. Appl., 251 (2000), 217-229.

[23] M. Aslam Noor, Equivalence of variational inclusions with resolvent equations, Nonl. Anal., 42 (2000), 963-970.

[24] M. ASLAM NOOR, Three-step iterative algorithms for multivalued quasi variational inclusions, J. Math. Anal. Appl., 255 (2001), 589-604.

[25] M. Aslam Noor, A Wiener-Hopf dynamical system for variational inequalities, New Zealand J. Math., 31 (2002), 173-182.

[26] M. Aslam NoOR, Resolvent dynamical systems for mixed variational inequalities, Korean J. Comput. Appl. Math., 9 (2002), 15-26.

[27] M. Aslam Noor, Fundamentals of mixed quasi variational inequalities, Inter. J. Pure Appl. Math., 15 (2004), 137-258.

[28] M. Aslam Noor, Some developments in general variational inequalities, Appl. Math. Comput., 152 (2004), 199-277.

[29] M. Aslam Noor, Differentiable nonconvex functions and general variational inequalities, Appl. Math. Comput., 199 (2008), 623-630.

[30] M. Aslam NoOR, A. BNOUHACHEM, On an iterative algorithm for general variational inequalities, Appl. Math. Comput., 185 (2007), 155-168.

[31] M. ASLAM NOOR AND K. INAYAT NOOR, On sensitivity analysis of general variational inequalities, Math. Comm., 13 (2008), 75-83.

[32] M. Aslam Noor AND K. InAYAT NooR, Projection algorithms for solving a system of general variational inequalities, Nonl. Anal. (2008).

[33] M. ASLAm NOOR AND K. INAYAT NoOR, Three-step iterative methods for general variational inclusions in $L^{p}$-spaces, J. Appl. Math. Computing, 27 (2008), 281-291.

[34] M. ASLAm NoOR AND K. INAYAT Noor, Multivalued variational inequalities and resolvent equations, Math. Computer Modelling, 26 (1997), 109-121.

[35] M. Aslam Noor, K. Inayat Noor, Sensitivity analysis for quasi variational inclusions, J. Math. Anal. Appl., 236 (1999), 290-299.

[36] M. Aslam NoOR AND TH. M. Rassias, Resolvent equations for set-valued variational inequalities, Nonl. Anal., 42 (2000), 71-83.

[37] M. Aslam Noor, K. Inayat Noor, Th. M. Rassias, Some aspects of variational inequalities, J. Comput. Appl. Math., 47 (1993), 285-312.

[38] M. Aslam Noor, K. InAyat Noor, Th. M. Rassias, Set-valued resolvent equations and mixed variational inequalities, J. Math. Anal. Appl., 220 (1998), 741-759.

[39] M. Aslam Noor, Y. J. Wang And N. XIU, Some new projection methods for variational inequalities, Appl. Math. Computation, 137 (2003), 423-435.

[40] M. Patriksson, Nonlinear Programming and Variational Inequalities: A Unified Approach, Kluwer Academic Publishers, Dordrecht, 1998.

[41] A. Pitonyok, P. SHI AND M. Shillor, On an iterative method for variational inequalities, Numer. Math., 58 (1990), 231-242.

[42] R. T. RockAfEllaR, Monotone operators and the proximal point algorithms, SIAM J. Control Optim., 14 (1976), 877-898. 
[43] P. SHI, Equivalence of Wiener-Hopf equations with variational inequalities, Proc. Amer. Math. Soc., 111 (1991), 339-346.

[44] G. Stampacchia, Formes bilineaires coercivities sur les ensembles convexes, C.R. Acad. Sci. Paris, 258 (1964), 4413-4416.

[45] W. TAKAHASHI, M. TOYODA, Weak convergence theorems for nonexpansive mappings and monotone mappings, J. Optim. Theory Appl., 118, 2 (2003), 417-428.

[46] X.L. WEnG, Fixed point iteration for local strictly pseudocontractive mappings, Proc. Amer. Math. Soc., 113 (1991), 727-731. 